\title{
Effects of the tumor suppressor PTEN on the pathogenesis of idiopathic pulmonary fibrosis in Chinese patients
}

\author{
BAOSONG XIE, GUANYING ZHENG, HONGRU LI, XIUJUAN YAO, \\ RUJUN HONG, RUIHUI LI, WENXIANG YUE and YUSHENG CHEN
}

Department of Respiratory Medicine, Fujian Provincial Hospital, Fujian Medical University, Fuzhou, Fujian 350001, P.R. China

Received March 2, 2015; Accepted December 23, 2015

DOI: $10.3892 / \mathrm{mmr} .2016 .4852$

\begin{abstract}
Idiopathic pulmonary fibrosis (IPF) is characterized by progressive interstitial fibrosis, and is associated with a fatal outcome. The critical pathological mechanisms underlying IPF are largely unknown; however, accumulating evidence has indicated similarities between IPF and cancer. Therefore, the present study examined the expression levels of the tumor suppressor phosphatase and tensin homolog deleted on chromosome 10 (PTEN) in Chinese patients with IPF, using an enzyme-linked immunosorbent assay. To determine the effects of PTEN on the development of pulmonary fibrosis, PTEN was overexpressed in transforming growth factor (TGF)- $\beta 1$-treated human embryonic lung fibroblasts (HFL-I cells). The serum levels of PTEN were significantly lower in 42 patients with IPF, as compared with in the healthy controls. In addition, PTEN overexpression enhanced apoptosis, and suppressed basal levels of proliferation and migration in fibroblasts. Notably, PTEN was able to specifically inhibit TGF- $\beta 1$-induced proliferation and migration of the cells. Overexpression of PTEN also suppressed phosphorylation of Akt and Smad3, and decreased the expression levels of numerous proteins with critical roles in TGF- $\beta 1$-induced fibrosis, including $\alpha$-smooth muscle actin, matrix metalloproteinase (MMP)-2 and MMP-9. These results indicated that PTEN may inhibit TGF- $\beta 1$-mediated myofibroblast differentiation of fibroblasts by attenuating signaling via the phosphatidylinositol 3-kinase/Akt and TGF- $\beta /$ Smad3 pathways.
\end{abstract}

\section{Introduction}

Idiopathic pulmonary fibrosis (IPF) is a progressive, fibrotic, interstitial lung disease of unknown cause, with a median survival time of $\sim 3$ years. The estimated incidence of IPF

Correspondence to: Dr Baosong Xie, Department of Respiratory Medicine, Fujian Provincial Hospital, Fujian Medical University, 134 Dongjie Street, Fuzhou, Fujian 350001, P.R. China

E-mail: xiebaosongresp@126.com

Key words: idiopathic pulmonary fibrosis, Phosphatase and tensin homolog deleted on chromosome 10 , overexpression, transforming growth factor- $\beta 1$, fibroblasts differentiation is 10 cases per 100,000 , with a prevalence of 30 cases per 100,000 (1). Progressive interstitial fibrosis is a hallmark of IPF, which results in a decline in lung function. Due to the unknown pathogenesis of this disease, patients with IPF have few treatment options. China is estimated to have the largest number of patients with IPF, which is due, at least in part, to its large population. Published epidemiological data for IPF in China are limited; however, known major risk factors include cigarette smoking and environmental exposure (2-4). Smoking strongly increases the occurrence of IPF, and China has one of the largest populations of smokers worldwide ( $\sim 350$ million). Furthermore, as a rapidly developing nation, Chinese individuals are exposed to high levels of vehicle exhaust, industrial emissions, and metal, wood and coal dusts, all of which can increase the likelihood of developing IPF. Fog and haze have rapidly increased in the North China Plain since 1954 (5), and airborne particulate matter (PM2.5) has become the focus of major public interest in China. Therefore, it is not surprising that the incidence of IPF is higher in China than it is in many other countries, and studies on the epidemiology and pathogenesis of IPF are critical and urgently required.

IPF is considered the most common and severe form of pulmonary fibrosis, which is characterized by the accumulation of extracellular matrix (ECM) proteins within the interstitium and alveolar space of the lungs. The pathology associated with pulmonary fibrosis is a consequence of the disturbance of two physiologically-balanced processes: The proliferation and apoptosis of fibroblasts, and the accumulation and breakdown of the ECM (6). Fibroblasts and fibroblast-derived myofibroblasts are the key effector cells in fibrogenesis, since they are major producers of ECM proteins. An overabundance of these cell types may contribute to the progression of pulmonary fibrosis. Furthermore, an increased number of fibroblastic foci, which are small aggregates of proliferating fibroblasts and myofibroblasts, has been reported to be associated with an increased risk of mortality in patients with IPF (7). To inhibit pulmonary fibrosis and to slow the progression of IPF, it is important to suppress the myofibroblast differentiation of fibroblasts and the subsequent ECM production.

Phosphatase and tensin homolog deleted on chromosome 10 (PTEN) is a tumor suppressor, the expression of which is lost in numerous types of human cancer. PTEN is able to strongly suppress cell migration (8), promote apoptosis (9), and inhibit cell growth (10). Recent studies have focused on 
the role of PTEN in IPF pathogenesis, due to the presence of some similarities between IPF and cancer, including IPF phenotype (11), global methylation patterns (12), and underlying disease mechanisms (13). White et al (14) reported that PTEN expression and phosphatase activity are diminished in fibroblasts isolated from patients with IPF. In addition, inhibition of PTEN in vivo promotes fibrosis, and PTEN inhibits myofibroblast differentiation in vitro $(14,15)$. PTEN is the primary negative regulator of the cell survival signaling pathway initiated by phosphatidylinositol 3-kinase (PI3K). Reduced PTEN expression and Akt hyperactivation have been detected in the alveolar epithelial cells and fibroblastic foci of human IPF lungs; additionally, low levels of PTEN expression/phosphatase activity have been shown to facilitate aberrant activation of the PI3K/Akt pathway and pathological proliferation of fibroblasts (16-19). Therefore, altered PTEN/PI3K/Akt signaling is considered to have a crucial role in IPF pathogenesis, thus suggesting that this pathway may be a potential therapeutic target for IPF.

Transforming growth factor (TGF) $-\beta$ is a cytokine with an important role in fibrosis. It promotes the differentiation of fibroblasts into myofibroblasts and enhances ECM protein synthesis (20-22). By binding to its receptor, TGF- $\beta$ triggers the activation of numerous signaling pathways, which contribute to progressive fibrosis, including the Smad pathway, the PI3K/Akt pathway, and the glycogen synthase kinase (GSK)-3 $\beta / \beta$-catenin pathway (22-25). TGF- $\beta$ suppresses PTEN expression $(19,26)$, and inhibition of PTEN activity is necessary for TGF- $\beta$-induced expression of $\alpha$-smooth muscle actin ( $\alpha$-SMA), which is a marker of myofibroblasts (15). However, the exact mechanism by which PTEN regulates the TGF- $\beta$-mediated transition of fibroblasts into myofibroblasts remains unclear.

PTEN has been implicated in the pathogenesis of IPF. Therefore, the present study hypothesized that there may be differences in PTEN serum levels between individuals with IPF and healthy individuals. If so, altered PTEN expression may serve as a diagnostic marker for IPF. In addition, we further hypothesized that altered PTEN expression may influence the production of $\alpha$-SMA and ECM proteins in TGF- $\beta$-treated lung fibroblasts, and that the PI3K/Akt signaling pathway may be associated with these PTEN-mediated effects.

A total of 42 Chinese patients with IPF and 42 healthy controls were included in the present study. Serum levels of PTEN were measured by enzyme-linked immunosorbent assay (ELISA), and comparisons between patients with IPF and healthy controls were made. To evaluate the role of PTEN in lung fibrosis, human embryonic lung fibroblasts were treated with TGF- $\beta 1$, in order to mimic pulmonary fibrosis. PTEN was overexpressed in TGF- $\beta 1$-treated human embryonic lung fibroblasts, and proliferation, apoptosis and migration were assayed. Western blotting was performed to examine PI3K/Akt and TGF- $\beta /$ Smad3 signaling, as well as the expression of downstream proteins, including the myofibroblast marker $\alpha$-SMA and matrix metalloproteinases (MMPs). The results of the present study suggested that low serum levels of PTEN may be used to diagnose IPF. Furthermore, PTEN overexpression was shown to inhibit TGF- $\beta 1$-induced fibroblast differentiation.

\section{Materials and methods}

Subjects. A total of 42 patients with IPF who were admitted to Fujian Province Hospital between June 2013 and April 2014 were enrolled in the present study. The clinical diagnosis of IPF was made by high-resolution computed tomography (HRCT) and pulmonary function tests, according to the guidelines presented by ATS/ERS/JRS/ALAT in 2011 (27). Patients were included in the study if they met the following two criteria: i) Absence of other known causes of interstitial lung disease (e.g., domestic and occupational environmental exposures, connective tissue disease and drug toxicity); ii) detection of usual interstitial pneumonia pattern by HRCT exam. Patients who were $<18$ years of age or who had other diseases, including phthisis, bronchogenic carcinoma, or other malignant tumors, were excluded from the study. A total of 42 healthy subjects were included as controls, based on the following criteria: i) Men and women who were $\geq 18$ years of age; ii) with no lung diseases. Subjects were excluded from participating as healthy controls if they were $<18$ years of age or if they presented with a malignant tumor. The present study was approved by the Medical Ethics Committee of Fujian Province Hospital (Fuzhou, China). Written informed consent was obtained from all patients and healthy subjects prior to inclusion in the study.

Pulmonary function tests. The following pulmonary function tests were conducted on all patients: Forced vital capacity (FVC); diffusing capacity of the lungs for carbon monoxide (DLCO), using a JAEGER ${ }^{\circledR}$ MasterScreen $^{\mathrm{TM}}$ Diffusion Pulmonary Function Analyzer (CareFusion Germany, Höchberg, Germany); and arterial partial pressure of oxygen $\left(\mathrm{PaO}_{2}\right)$, using an ABL800 BASIC Arterial Blood Gas Analyzer (Radiometer Medical ApS, Brønshøj, Denmark). FVC and DLCO measurements are expressed as percentages of predicted values.

Measurement of D-dimer levels. Plasma concentrations of D-dimer were measured using a latex-enhanced immuno turbidimetric assay. Cells were removed from plasma by centrifugation at 2,000 $\mathrm{x}$ g for $10 \mathrm{~min}$ and samples were prepared according to the manufacturer's protocol (Liatest D-Di 113837; Diagnostica Stago, Asnières, France). Sample values were measured using a STA-R Evolution Automated Blood Coagulation Analyzer (Stago, Paris, France).

Detection of serum PTEN levels by ELISA. Venous blood samples $(5 \mathrm{ml})$ were collected and PTEN ELISA assays (Colorfulgene Biotechnology, Inc., Wuhan, China) were performed using the Multiskan MK3 enzyme-labeled instrument (Thermo Fisher Scientific, Inc., Vantaa, Finland). Briefly, the test samples were thawed to room temperature, and 100- $\mu$ l aliquots of each sample were added into monoclonal antibody-coated 96-well plates. Following incubation at $37^{\circ} \mathrm{C}$ for $60 \mathrm{~min}$, the closure plate membrane was uncovered and the liquid was discarded and subsequently dried by manually swinging the plates in the air. Subsequently, each well was supplemented with washing buffer, left for $30 \mathrm{sec}$ then drained. This was repeated five times and the plates were dried by patting. Each well was supplemented with $50 \mu \mathrm{l}$ horseradish peroxidase (HRP)-conjugated anti-PTEN antibody and shaken prior to incubation at $37^{\circ} \mathrm{C}$ for $60 \mathrm{~min}$, and the washing step outlined above was repeated. Subsequently, 
$100 \mu \mathrm{l}$ chromogen solution was added to each well and incubated for $15 \mathrm{~min}$, prior to the addition of $50 \mu \mathrm{l}$ termination solution per well. The plates were shaken on a shaker for $5 \mathrm{sec}$ in order to thoroughly mix the substrate and termination solutions. The absorbance of the reaction mixture was measured at $450 \mathrm{~nm}$ wavelength (A value) using a Multiskan MS 252 microplate reader (Thermo Fisher Scientific, Inc., Waltham, MA, USA).

Cell culture. The HFL-I human embryonic lung fibroblast cell line was purchased from Cell Bank of the Chinese Academy of Sciences (Beijing, China). The cells were maintained in F12K medium (Sigma-Aldrich, St. Louis, MO, USA) supplemented with $10 \%$ fetal bovine serum (FBS; Gibco; Thermo Fisher Scientific, Inc.) and 1\% penicillin/streptomycin (Beijing Solarbio Science \& Technology Co., Ltd., Beijing, China).

Plasmid construction and transfection. To generate the PTEN expression vector pcDNA3.1-PTEN, the PTEN coding region was amplified from cDNA by PCR using the following primers: Forward, 5'-CGG AAT TCC ATG ACA GCCATC ATCAAAGAG-3' and reverse, 5'-CCCTCGAGGTCAGACTTTTGTAATTTGTGT-3' (Shanghai Generay Biotech Co., Ltd., Shanghai, China). The PCR product was digested using EcoRI and XhoI (both Thermo Fisher Scientific, Inc.) and cloned into the pcDNA3.1(+) green fluorescent protein vector (JRDUN Biotechnology Co., Ltd., Shanghai, China).

One day prior to transfection, HFL-1 cells were plated in 6 -well dishes at $5 \times 10^{5}$ cells/well. The cells were transfected with either $2 \mu \mathrm{g}$ PTEN overexpression vector (PTEN) or with a control vector (Vec; Addgene, Inc., Cambridge, MA, USA); an untransfected control group (Con) was also included. Cells were harvested with trypsin (Kilton Biological Technology Co., Ltd.) $48 \mathrm{~h}$ post-transfection, and total RNA was extracted from the cells.

TGF- $\beta 1$ stimulation was performed $48 \mathrm{~h}$ post-transfection. TGF- $\beta 1$ (5 ng/ml; cat. no. PHG9204; Invitrogen; Thermo Fisher Scientific, Inc.) was added to the cells of all transfection groups: PTEN overexpression $(\mathrm{P}+\mathrm{T})$, control vector $(\mathrm{V}+\mathrm{T})$, or untransfected cells (TGF). A total of $24 \mathrm{~h}$ post-stimulation, the cells were harvested and subjected to analysis by apoptosis assay and western blotting.

Reverse transcription-quantitative polymerase chain reaction (RT-qPCR). Total RNA was extracted from the cells using TRIzol ${ }^{\circledR}$ reagent (Invitrogen; Thermo Fisher Scientific, Inc., Shanghai, China) and was reverse transcribed using an RT kit (Thermo Fisher Scientific, Inc., Shanghai, China), according to the manufacturer's protocol. SYBR Green PCR kit (Thermo Fisher Scientific, Inc., Shanghai, China) was used to conduct RT-qPCR. The following sequence-specific primers were used: PTEN, forward 5'-TCAGGCGAGGGAGATGAGAG-3' and reverse 5'-CGAAGAGGAGGCGAGAAACG-3'; and glyceraldehyde 3-phosphate dehydrogenase (GAPDH), forward 5'-CAC CCACTCCTCCACCTTTG-3' and reverse 5'-CCACCACCC TGTTGCTGTAG-3' (Shanghai Generay Biotech Co., Ltd.). qPCR was performed on an ABI-7300 Real-Time PCR instrument (Applied Biosystems; Thermo Fisher Scientific, Inc., Waltham, MA, USA) with the following thermal cycling conditions: $95^{\circ} \mathrm{C}$ for $5 \mathrm{~min}$, followed by 40 cycles of $95^{\circ} \mathrm{C}$ for $15 \mathrm{sec}$ and $60^{\circ} \mathrm{C}$ for $45 \mathrm{sec}, 95^{\circ} \mathrm{C}$ for $15 \mathrm{sec}, 60^{\circ} \mathrm{C}$ for $1 \mathrm{~min}, 95^{\circ} \mathrm{C}$ for $15 \mathrm{sec}$ and $60^{\circ} \mathrm{C}$ for $15 \mathrm{sec}$. Relative differences in gene expression between the groups were calculated using the quantification cycle $(\mathrm{Cq})$ method. Data analysis was performed using the $2^{-\Delta \Delta \mathrm{Cq}}$ method (28), and GAPDH mRNA was used for normalization. All experiments were repeated three times.

Cell viability assay. Cell viability was assessed using a Cell Counting kit (CCK)-8 assay (Dojindo Molecular Technologies Co., Ltd., Kumamoto, Japan). The cells were seeded in 96-well plates supplemented with F12K serum-free medium (Sigma-Aldrich) at a density of $1-5 \times 10^{4}$ cells per well. CCK-8 and medium were mixed at a ratio of 10:100 $\mu \mathrm{l}$ per well in sterile Eppendorf tubes. Medium was aspirated, and the cells were washed once with phosphate-buffered saline (PBS). Subsequently, premixed CCK- 8 and medium were added to each well and incubated at $37^{\circ} \mathrm{C}$ for $0.5-1 \mathrm{~h}$. Absorbance values at $450 \mathrm{~nm}$ were obtained using an automatic LabSystems 352 Multiskan MS microplate reader (Thermo Fisher Scientific, Inc.).

Apoptosis assay. Apoptosis of HFL-1 cells was determined using flow cytometry. The cells were scraped, washed twice with PBS, and centrifuged at $1,000 \mathrm{x}$ g for $5 \mathrm{~min}$ at $4^{\circ} \mathrm{C}$. Pelleted cells were incubated in $1 \mathrm{X}$ binding buffer containing fluorescein isothiocyanate (FITC)-Annexin V and propidium iodide (BD Biosciences, San Jose, CA, USA) in the dark for $15 \mathrm{~min}$. Apoptotic cells were examined using a FACSCalibur flow cytometer (BD Biosciences) and analyzed with FlowJo software (version 7.6.1; FlowJo, LLC, Ashland, OR, USA). A minimum of $1 \times 10^{4}$ events per sample were acquired and analyzed. Three independent experiments were performed. Values are expressed as the mean \pm standard error of the mean in three separate experiments.

Cell migration assay. HFL-1 cells were left untransfected or transfected with either a PTEN overexpression vector or a control vector. A total of $48 \mathrm{~h}$ post transfection, Transwell migration assays were performed. Following trypsinization, cells in the logarithmic growth phase were suspended in F12K serum-free medium containing $0.5 \%$ FBS. A $100 \mu 1$ cell suspension $\left(1.0 \times 10^{5}\right.$ cells $\left./ \mathrm{ml}\right)$ was added to the upper chamber of the Transwell system, and $500 \mu \mathrm{l}$ medium containing $10 \%$ FBS was added to the lower chamber. Following $16 \mathrm{~h}$ culture, the upper chamber was removed, and washed three times with PBS. The cells of the upper chamber were gently wiped with a cotton swab and cells that had migrated to the lower chamber were fixed with $4 \%$ paraformaldehyde for $30 \mathrm{~min}$ and subsequently stained with crystalline violet for $15 \mathrm{~min}$. Four fields (magnification, $\mathrm{x} 200$ ) were randomly selected to quantify the number of cells that had successfully migrated to the lower chamber, using an Olympus CX41 (Olympus Corporation, Tokyo, Japan).

Western blot analysis. Western blotting was performed to detect both total and phosphorylated forms of numerous proteins of interest. Proteins were extracted from the cells using RAPI protein extraction medium (Solarbio R0010; Beijing Solarbio Science \& Technology Co., Ltd.). Protein concentration was determined by Bradford assay using the Bio-Rad Protein Assay Dye Reagent Concentrate (Bio-Rad Laboratories, Inc. Hercules, 
CA, USA), according to the manufacturer's protocol. Total cell protein extracts $(25 \mu \mathrm{g})$ were separated by $12 \%$ sodium dodecyl sulfate-polyacrylamide gel electrophoresis and were then transferred to nitrocellulose membranes (EMD Millipore, Billerica, MA, USA). The blots were blocked with 5\% nonfat milk overnight, and were then incubated overnight at $4^{\circ} \mathrm{C}$ with the following primary antibodies: Anti-PTEN (ab32199), anti- $\alpha$-SMA (both 1:500; ab5694; both Abcam, Cambridge, MA, USA), anti- $\beta$-catenin $(1: 1,000 ; 8814 S$; Cell Signaling Technology, Inc., Beverly, MA, USA), anti-Smad3 (1:400; ab28379), anti-phosphorylated (p)-Smad3 (1:500; ab63403; both Abcam), anti-Akt (9272S), anti-p-Akt (4058S; both Cell Signaling Technology, Inc.), anti-MMP-2 (1948S; Epitomics, Inc., Burlingame, CA, USA), anti-MMP-9 (all 1:1,000; ab38898; Abcam), and anti-GAPDH (1:1,500; 5471; Cell Signaling Technology, Inc.). The following day, membranes were incubated at room temperature for $1 \mathrm{~h}$ with HRP-conjugated goat anti-rabbit (A0208) or anti-mouse immunoglobulin G secondary antibodies (both 1:1,000; A0216; both Beyotime Institute of Biotechnology, Shanghai, China). After washing with PBS, the blots were visualized using Pierce Enhanced Chemiluminescence Western blotting substrate (Pierce Protein Biology; Thermo Fisher Scientific, Inc., Rockford, IL, USA), according to the manufacturer's protocol. Densitometric analysis of immunoblots was performed using TotalLab Software, version 2.00 (TotalLab Limited, Newcastle upon Tyne, UK). The densitometry values of the proteins of interest were normalized to those of GAPDH. All experiments were repeated three times.

Statistical analysis. Statistical analysis was performed using SPSS 19.0 software (SPSS IBM, Armonk, NY, USA). All data are presented as the mean \pm standard deviation. One-factor analysis of variance was used for multiple comparisons, and the least significant difference test was used for intra-group comparisons. $\mathrm{P}<0.05$ was considered to indicate a statistically significant difference.

\section{Results}

Baseline clinical characteristics and serum expression of PTEN in patients with IPF. Baseline characteristics, including age, gender, smoking status, diabetic status and hypertensive status, were similar between patients with IPF and healthy controls (Table I). Although each of these baseline characteristics was higher in the IPF patient group, there were no significant differences when compared to the controls. Conversely, the prevalence of coronary heart disease was significantly higher in patients with IPF, as compared with in healthy subjects $(\mathrm{P}<0.05)$, which is consistent with an earlier report (29).

To evaluate the expression levels of PTEN in each of the two study groups, serum samples were collected and analyzed by ELISA. Serum PTEN protein expression levels were significantly reduced in patients with IPF, as compared with in healthy subjects $(\mathrm{P}<0.01$; Table I).

Effects of PTEN overexpression on TGF- $\beta 1$-induced lung fibroblasts. The role of PTEN in fibrosis was examined by overexpressing PTEN in human embryonic lung fibroblasts.
Following transfection of the cells with PTEN, overexpression was confirmed at both the mRNA and protein level (Fig. 1).

Subsequently, TGF- $\beta 1$-stimulated HFL-1 cells were used to examine the effects of PTEN overexpression on lung fibrosis. Fibroblast proliferation is a primary event in fibrosis; therefore, HFL-1 cell viability was assessed. As shown in Fig. 2, HFL-1 cell proliferation was significantly enhanced following 24 or $48 \mathrm{~h}$ of TGF- $\beta 1$ stimulation $(\mathrm{P}<0.05)$. These effects on proliferation are consistent with the effects of TGF- $\beta 1$ on the induction of fibrosis. Overexpression of PTEN significantly reduced HFL-1 cell proliferation at both 24 and $48 \mathrm{~h}(\mathrm{P}<0.01)$, and attenuated TGF- $\beta 1$-mediated proliferation at the $48 \mathrm{~h}$ time point $(\mathrm{P}<0.05)$.

An apoptosis analysis was also performed following PTEN overexpression and TGF- $\beta 1$ stimulation. Treatment with TGF- $\beta 1$ decreased apoptosis of HFL- 1 cells; conversely, overexpression of PTEN enhanced apoptosis of the cells both in the absence or presence of TGF- $\beta 1$ stimulation (Fig. 3). These results indicate that PTEN may inhibit fibrosis by both inhibiting proliferation and promoting apoptosis of fibroblasts.

The present study examined the role of PTEN in fibroblast migration by performing a Transwell migration assay following PTEN overexpression. As shown in Fig. 4, TGF- $\beta 1$ stimulation significantly increased the migration of HFL-1 cells, as compared with the control groups $(\mathrm{P}<0.01)$. Conversely, overexpression of PTEN significantly suppressed cell migration both in the presence or absence of TGF- $\beta 1$ stimulation $(\mathrm{P}<0.01)$.

These results suggest that PTEN overexpression enhances apoptosis and suppresses proliferation and migration of TGF- $\beta 1$-induced fibroblasts. Therefore, PTEN may function as an inhibitor of fibroblast differentiation.

Effects of PTEN overexpression on $p$-Akt, p-Smad3, $\beta$-catenin, $\alpha$-SMA, MMP-2 and MMP-9. To further evaluate the role of PTEN in TGF- $\beta 1$-induced fibroblasts, the effects of PTEN overexpression were determined on several signaling pathways. As shown in Fig. 5, phosphorylation of Akt and Smad3 was significantly increased following TGF- $\beta 1$ stimulation $(\mathrm{P}<0.01)$; notably, these increases were attenuated by PTEN overexpression $(\mathrm{P}<0.01)$. The expression levels of several TGF- $\beta 1$-induced proteins, including $\alpha$-SMA, MMP-2 and MMP-9, were also significantly attenuated by PTEN overexpression $(\mathrm{P}<0.01)$. The protein expression levels of $\beta$-catenin were not significantly altered in TGF- $\beta 1$-stimulated HFL-1 cells (data not shown). These data indicate that PTEN overexpression may suppress TGF- $\beta 1$-induced target protein expression by inhibiting phosphorylation of Akt and Smad3, two downstream targets of TGF- $\beta 1$ signaling.

\section{Discussion}

The present study examined the expression levels of PTEN in clinical cases of IPF, and determined the effects of PTEN overexpression on a TGF- $\beta 1$-induced fibroblast model of IPF pathogenesis. PTEN serum levels were significantly lower in patients with IPF, as compared with in healthy control subjects, thus suggesting that PTEN may be a useful diagnostic marker for IPF. Treatment of human fibroblasts with TGF- $\beta 1$ promotes their differentiation into myofibroblasts. 
Table I. Baseline clinical characteristics of study subjects.

\begin{tabular}{lccc}
\hline Characteristic & IPF patients $(\mathrm{n}=42)$ & Healthy subjects $(\mathrm{n}=42)$ & P-value \\
\hline Age (years) & $67.9 \pm 11.7$ & $65.5 \pm 8.9$ & 0.296 \\
Gender (men/women) & $31 / 11$ & $13 / 42(30.95)$ & 0.474 \\
Smoking $(\%)$ & $15 / 42(35.71)$ & - & 0.643 \\
Pulmonary function tests & & - & - \\
FVC $(\%$ pred) & $67 \pm 10$ & $7 / 42(16.67)$ \\
DLCO $(\%$ pred) & $54 \pm 17$ & $15 / 42(35.71)$ \\
PaO $(\mathrm{mmHg})$ & $73.26 \pm 11.65$ & $3 / 42(7.14)$ \\
Diabetes $(\%)$ & $8 / 42(19.05)$ & - \\
Hypertension $(\%)$ & $17 / 42(40.48)$ & $0.37 \pm 0.23$ \\
Coronary heart disease $(\%)$ & $15 / 42(35.71)$ & 0.653 \\
D-dimer $(\mu \mathrm{g} / \mathrm{ml})$ & $1.23 \pm 1.02$ & 0.001 \\
Serum PTEN $(\mathrm{ng} / \mathrm{ml})$ & $8.11 \pm 0.24$ & $<0.001$ \\
\hline
\end{tabular}

-, not tested; FVC, forced vital capacity; DLCO, diffusing capacity of the lungs for carbon monoxide; $\mathrm{PaO}_{2}$, partial pressure of oxygen; \% pred, percentage of predicted values.
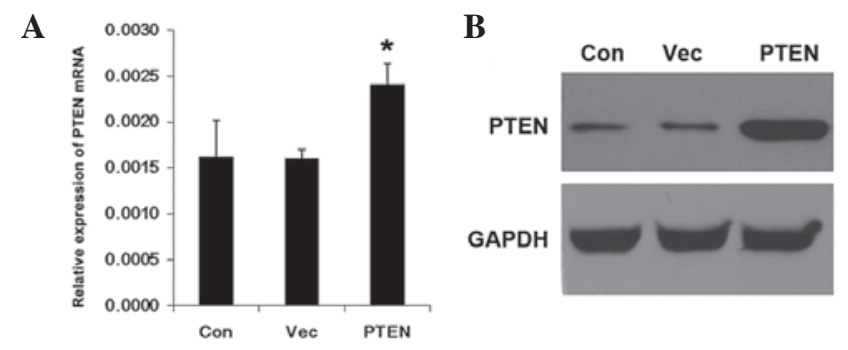

Figure 1. Overexpression of phosphatase and tensin homolog deleted on chromosome 10 (PTEN) in human embryonic lung fibroblasts. HFL-1 cells were transfected with a PTEN overexpression vector (PTEN), a control vector (Vec), or remained untransfected (control cells; Con). A total of $48 \mathrm{~h}$ post-transfection, the cells were harvested and PTEN expression was analyzed by (A) reverse transcription-quantitative polymerase chain reaction and (B) western blotting. Glyceraldehyde 3-phosphate dehydrogenase (GAPDH) served as a loading control. Data are presented as the mean \pm standard deviation.
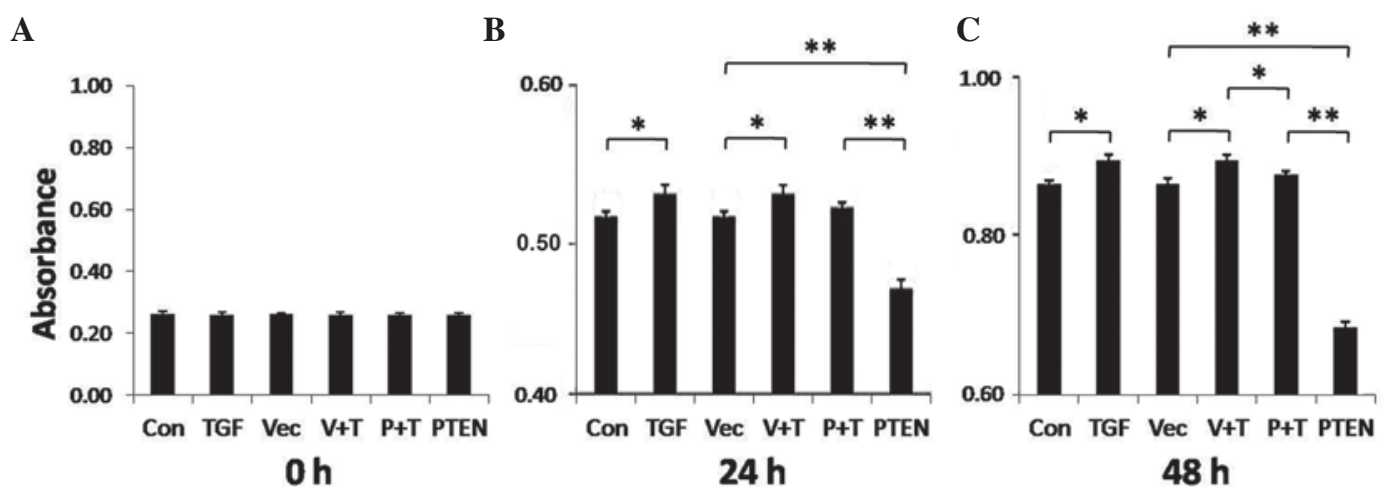

Figure 2. Cell viability assay of transforming growth factor (TGF)- $\beta 1$-stimulated fibroblasts after phosphatase and tensin homolog deleted on chromosome 10 (PTEN) overexpression. HFL-1 cells were transfected with a PTEN overexpression vector, a control vector, or remained untransfected. A total of $48 \mathrm{~h}$ post-transfection, the cells were treated with $5 \mathrm{ng} / \mathrm{ml} \mathrm{TGF}-\beta 1$ or were left untreated for (A) $0 \mathrm{~h}$, (B) $24 \mathrm{~h}$, or (C) $48 \mathrm{~h}$. Cell proliferation was analyzed by Cell Counting kit- 8 assay. The experiment was repeated three times. Data are presented as the mean \pm standard deviation $(\mathrm{n}=3)$. ${ }^{*} \mathrm{P}<0.05$, ${ }^{* * *} \mathrm{P}<0.01$. Con, control; TGF, TGF- $\beta 1$ stimulation; Vec, vector control; V + T, vector control + TGF- $\beta 1$ stimulation; P + T, PTEN overexpression vector + TGF- $\beta 1$ stimulation; PTEN, PTEN overexpression vector.

The results of the present study demonstrated that PTEN overexpression inhibits fibroblast proliferation and migration, and enhances apoptosis. In addition, PTEN may inhibit TGF- $\beta 1$-induced fibrosis via suppressing the phosphorylation 
A
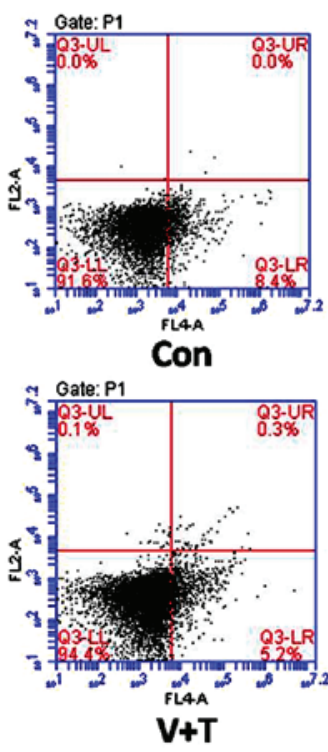

B

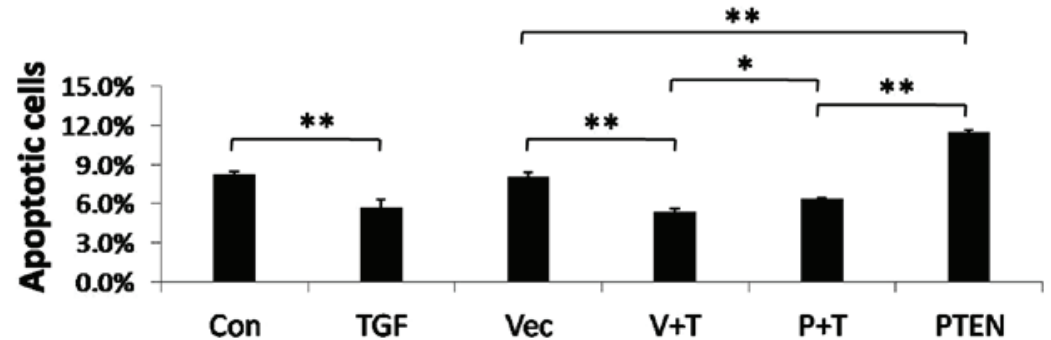

Figure 3. Apoptosis analysis of transforming growth factor (TGF)- $\beta 1$-stimulated fibroblasts after phosphatase and tensin homolog deleted on chromosome 10 (PTEN) overexpression. HFL-1 cells were transfected with a PTEN overexpression vector, a control vector, or remained untransfected. A total of $48 \mathrm{~h}$ post-transfection, the cells were treated with $5 \mathrm{ng} / \mathrm{ml}$ TGF- $\beta 1$ or were left untreated for $24 \mathrm{~h}$. (A) Apoptosis was measured by surface Annexin V staining and flow cytometry. (B) Data represent the results of three independent experiments. Data are presented as the mean \pm standard error of the mean. ${ }^{*}<0.05,{ }^{* *} \mathrm{P}<0.01$. Con, control; TGF, TGF- $\beta 1$ stimulation; Vec, vector control; V + T, vector control + TGF- $\beta 1$ stimulation; $\mathrm{P}+\mathrm{T}$, PTEN overexpression vector $+\mathrm{TGF}-\beta 1$ stimulation; PTEN, PTEN overexpression vector.

of downstream targets of TGF- $\beta 1$, including Akt and Smad3. Consistent with this, several TGF- $\beta 1$ target proteins, including $\alpha$-SMA, MMP-2 and MMP-9, were revealed to be downregulated. These data establish an important inhibitory role for PTEN in pulmonary fibrosis. PTEN may prove to be a useful diagnostic marker for IPF, and components of the PTEN/PI3K/Akt signaling pathway may serve as potentially novel therapeutic targets for the treatment of IPF.

PTEN, which is a tumor suppressor that functions as a dual protein/lipid phosphatase, negatively regulates the cell survival signaling pathway initiated by PI3K. As an important modulator of apoptosis, cell growth, migration and invasion, PTEN deficiency suppresses apoptosis, and enhances cell proliferation and migration (8-10). The present study detected reduced serum levels of PTEN in patients with IPF. Overexpression of PTEN in TGF- $\beta 1$-induced fibroblasts resulted in increased apoptosis, decreased proliferation and migration, and reduced expression of $\alpha$-SMA. These findings are consistent with the findings of a previous study in IPF fibroblasts and pten ${ }^{-/}$fibroblasts (15). Taken together, PTEN may have a critical role in IPF pathogenesis via the inhibition of fibroblast differentiation into myofibroblasts.

Previous studies have highlighted the importance of the PTEN/PI3K/Akt pathway in lung injury and fibrosis $(16,18)$. For example, reduced PTEN expression/activity and Akt hyperactivation have been described in IPF fibroblasts; findings such as this help establish the importance of PTEN/PI3K/Akt axis in IPF pathogenesis (30). In addition, immunohistochemical analysis of IPF lung tissue identified high Akt activity and inactive forkhead box O3a (a transcription factor downstream of the PI3K/Akt pathway) in patients with IPF (31). TGF- $\beta$ is believed to be a key mediator of tissue fibrosis as a consequence of ECM accumulation in pathological states (32). It has been demonstrated that inhibition of PTEN activity is necessary for TGF- $\beta$-induced $\alpha$-SMA expression (15). However, the mechanisms underlying PTEN-inhibited differentiation of TGF- $\beta$-induced fibroblasts remain elusive. In the present study, PTEN was overexpressed in human lung fibroblasts, and the activity of Akt was examined following TGF- $\beta 1$ stimulation. PTEN overexpression was able to suppress TGF- $\beta 1$-induced Akt phosphorylation. Inhibition of PI3K has also been shown to prevent proliferation and differentiation of TGF- $\beta$-treated human lung fibroblasts into myofibroblasts (33). Wilkes et al (34) reported that the PI3K/Akt pathway can be activated by TGF- $\beta$ via the phosphorylation of Akt, and that this signaling cascade has an important role in TGF- $\beta$-mediated fibroblast proliferation and morphological transformation. This activation appears to be independent of Smad2/3 activation (34). Notably, the present study demonstrated that overexpression of PTEN 


\section{A}

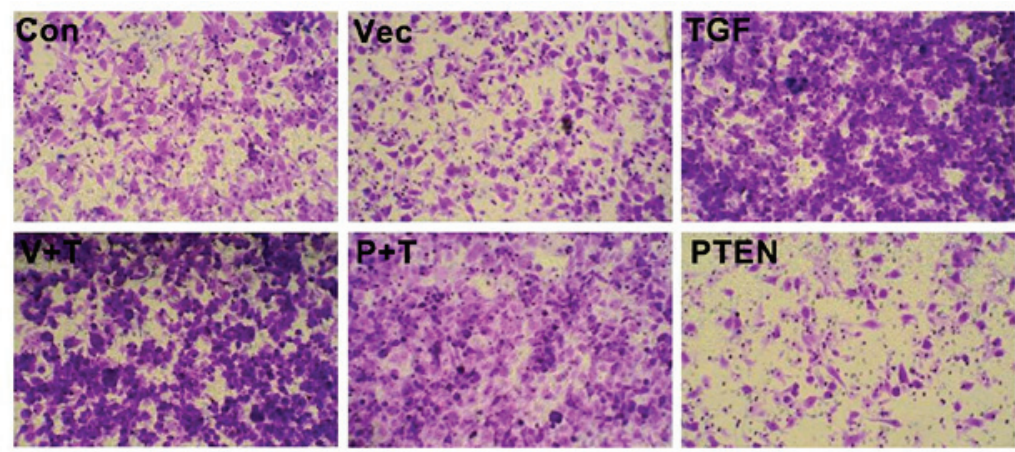

B

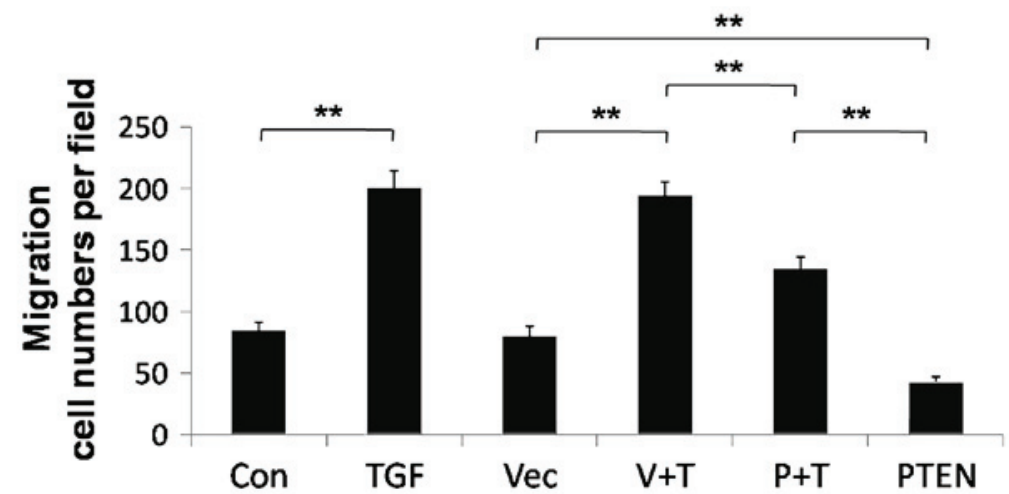

Figure 4. Phosphatase and tensin homolog deleted on chromosome 10 (PTEN) inhibits transforming growth factor (TGF)- $\beta 1$-induced fibroblast migration. HFL-1 cells were transfected with a PTEN overexpression vector, a control vector, or remained untransfected. A total of $24 \mathrm{~h}$ post-transfection, the cells were plated in Transwell inserts and were incubated for $24 \mathrm{~h}$. Cells were then treated with $5 \mathrm{ng} / \mathrm{ml} \mathrm{TGF}$ - $\beta 1$ or were left untreated for $24 \mathrm{~h}$. (A) Migratory cells were fixed, stained and images were captured (magnification, x100). (B) Cells from three different fields were counted, and averages of three independent experiments were plotted. Data are presented as the mean \pm standard deviation. ${ }^{* *} \mathrm{P}<0.01$. Con, control; TGF, TGF- $\beta 1$ stimulation; Vec, vector control; V + T, vector control + TGF- $\beta 1$ stimulation; P + T, PTEN overexpression vector + TGF- $\beta 1$ stimulation; PTEN, PTEN overexpression vector.
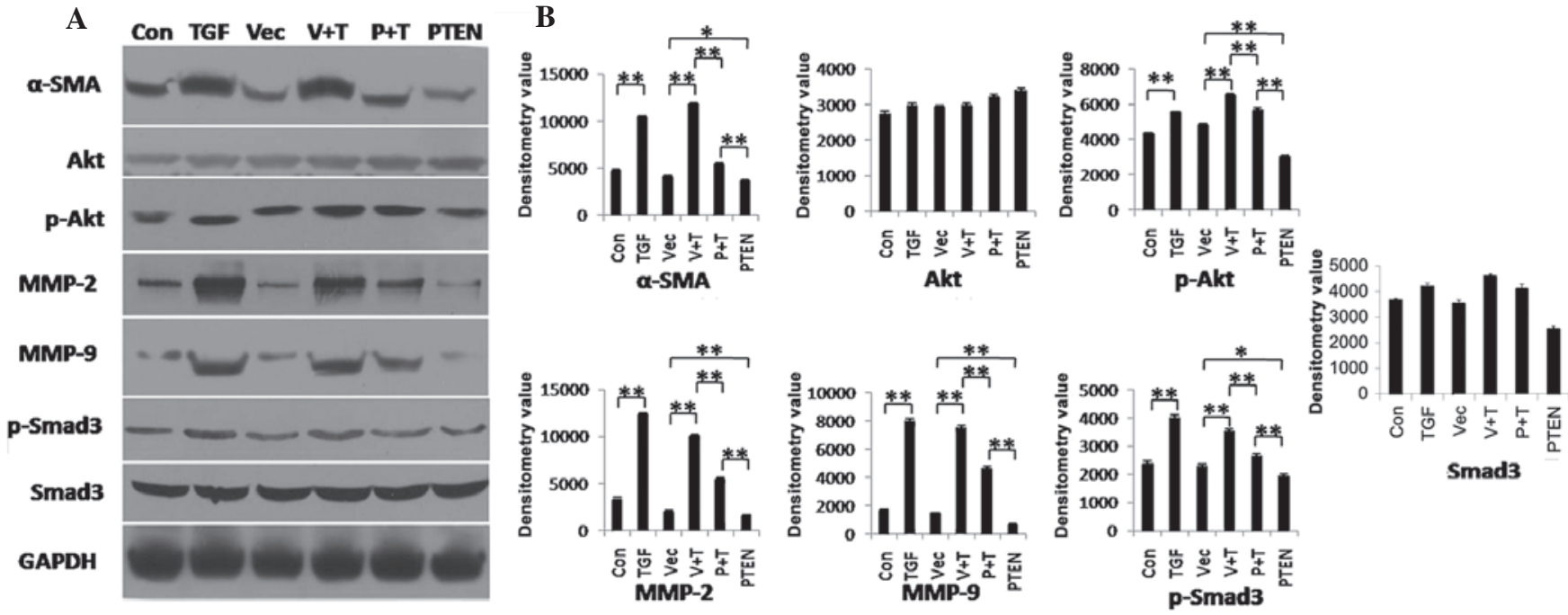

Figure 5. Overexpression of phosphatase and tensin homolog deleted on chromosome 10 (PTEN) suppresses phosphorylation (p-) of Akt and Smad3, and the expression of $\alpha$-smooth muscle actin ( $\alpha$-SMA), matrix metalloproteinase (MMP)- 2 and MMP-9 in transforming growth factor (TGF)- $\beta 1$-induced fibroblasts HFL-1 cells were transfected with a PTEN overexpression vector, a control vector, or remained untransfected. A total of $48 \mathrm{~h}$ post-transfection, cells were treated with $5 \mathrm{ng} / \mathrm{ml}$ TGF- $\beta 1$ or were left untreated for $24 \mathrm{~h}$. (A) Cell lysates were collected and subjected to western blotting. (B) Densitometry data from three independent experiments are plotted. Glyceraldehyde 3-phosphate dehydrogenase (GAPDH) served as a loading control. Data are presented as the mean \pm standard deviation $(\mathrm{n}=3)$. " $\mathrm{P}<0.05,{ }^{* *} \mathrm{P}<0.01$. Con, control; TGF, TGF- $\beta 1$ stimulation; Vec, vector control; $\mathrm{V}+\mathrm{T}$, vector control + TGF- $\beta 1$ stimulation; $\mathrm{P}+\mathrm{T}, \mathrm{PTEN}$ overexpression vector + TGF- $\beta 1$ stimulation; PTEN, PTEN overexpression vector.

suppressed TGF- $\beta 1$-mediated phosphorylation of Smad3. TGF- $\beta 1 /$ Smad3 has been shown to be a major pathway regulating myofibroblast differentiation (35). Therefore, PTEN may suppress TGF- $\beta 1$-induced myofibroblast differentiation by inhibiting both the PI3K/Akt pathway and the TGF- $\beta /$ Smad3 pathway.

Aberrant activation of Wnt/ $\beta$-catenin signaling has been detected in patients with IPF (36), and signaling via 
GSK- $3 \beta / \beta$-catenin is associated with TGF- $\beta 1$-mediated differentiation of human lung fibroblasts into myofibroblasts (24). The present study also examined the expression levels of $\beta$-catenin; however, PTEN overexpression had no significant effect on $\beta$-catenin levels in TGF- $\beta 1$-induced fibroblasts. Therefore, in contrast to previous reports $(24,37,38)$, $\beta$-catenin was not upregulated by TGF- $\beta 1$ in the present study. This may be due to differences in human embryonic lung fibroblasts and lung fibroblasts derived from patients with IPF. Further studies are required to explore the role of $\mathrm{Wnt} / \beta$-catenin signaling in the pathogenesis of IPF.

IPF is associated with the deposition of ECM components into the lung interstitium. MMPs are known to have a central role in ECM remodeling. MMP-2 and MMP-9, collectively known as the gelatinases, are highly expressed in IPF (39), and both were significantly upregulated by TGF- $\beta 1$ stimulation in the present study. Overexpression of PTEN in TGF- $\beta 1$-induced fibroblasts resulted in inhibition of MMP-2 and MMP-9 expression, suggesting a role for PTEN in ECM remodeling. Certain limitations of our study should be noted. Due to the relatively small sample size $(n=42)$, there is limited statistical power to detect putative associations between patients with IPF and healthy subjects. For example, smoking status and diabetic status, which have previously been shown to be strongly associated with IPF $(2,4,15)$, were not significantly different between cases and controls in the present study. This limitation will be addressed in future studies, in which we plan to enroll larger numbers of individuals. A second potential limitation is that the studies were performed in only human embryonic lung fibroblasts. Additional in vivo studies or studies using lung fibroblasts from patients with IPF are required to further investigate PTEN function in IPF.

In conclusion, the present study demonstrated that PTEN expression is reduced in patients with IPF, as compared with in healthy individuals. In addition, PTEN overexpression inhibits TGF- $\beta 1$-mediated myofibroblast differentiation of fibroblasts by attenuating signaling via the PI3K/Akt and TGF- $\beta /$ Smad3 pathways. These results suggested that PTEN may be a useful diagnostic marker for IPF and that the PI3K pathway may be a target for therapeutic intervention for the disease. Notably, a previous study recently described a translational preclinical animal model of IPF (40), which may be a useful model for the exploration of anti-PI3K/Akt therapies in vivo.

\section{Acknowledgements}

The present study was supported by the Project of Natural Science Fund of Fujian Province (grant no. 2012J01321).

\section{References}

1. Gay SE, Kazerooni EA, Toews GB, Lynch JP III, Gross BH, Cascade PN, Spizarny DL, Flint A, Schork MA, Whyte RI, et al: Idiopathic pulmonary fibrosis: Predicting response to therapy and survival. Am J Respir Crit Care Med 157: 1063-1072, 1998.

2. Baumgartner KB, Samet JM, Stidley CA, Colby TV and Waldron JA: Cigarette smoking: A risk factor for idiopathic pulmonary fibrosis Am J Respir Crit Care Med 155: 242-248, 1997.

3. Iwai K, Mori T, Yamada N, Yamaguchi M and Hosoda Y: Idiopathic pulmonary fibrosis. Epidemiologic approaches to occupational exposure. Am J Respir Crit Care Med 150: 670-675, 1994.
4. Taskar VS and Coultas DB: Is idiopathic pulmonary fibrosis an environmental disease? Proc Am Thorac Soc 3: 293-298, 2006.

5. Quan J, Zhang Q, He H, Liu J, Huang M and Jin H: Analysis of the formation of fog and haze in North China Plain (NCP). Atmos Chem Phys 11: 8205-8214, 2011.

6. Todd NW, Luzina IG and Atamas SP: Molecular and cellular mechanisms of pulmonary fibrosis. Fibrogenesis Tissue Repair 5: 11,2012

7. King TE Jr, Schwarz MI, Brown K, Tooze JA, Colby TV, Waldron JA Jr, Flint A, Thurlbeck W and Cherniack RM: Idiopathic pulmonary fibrosis: Relationship between histopathologic features and mortality. Am J Respir Crit Care Med 164: 1025-1032, 2001.

8. Tamura M, Gu J, Matsumoto K, Aota S, Parsons R and Yamada KM: Inhibition of cell migration, spreading, and focal adhesions by tumor suppressor PTEN. Science 280: 1614-1617, 1998.

9. Stambolic V, Suzuki A, de la Pompa JL, Brothers GM, Mirtsos C, Sasaki T, Ruland J, Penninger JM, Siderovski DP and Mak TW: Negative regulation of PKB/Akt-dependent cell survival by the tumor suppressor PTEN. Cell 95: 29-39, 1998.

10. Tamura M, Gu J, Takino T and Yamada KM: Tumor suppressor PTEN inhibition of cell invasion, migration, and growth: Differential involvement of focal adhesion kinase and p130Cas. Cancer Res 59: 442-449, 1999.

11. Vancheri C, Failla M, Crimi N and Raghu G: Idiopathic pulmonary fibrosis: A disease with similarities and links to cancer biology. Eur Respir J 35: 496-504, 2010.

12. Rabinovich EI, Kapetanaki MG, Steinfeld I, Gibson KF, Pandit KV, Yu G, Yakhini Z and Kaminski N: Global methylation patterns in idiopathic pulmonary fibrosis. PLoS One 7: e33770, 2012.

13. Vancheri C: Common pathways in idiopathic pulmonary fibrosis and cancer. Eur Respir Rev 22: 265-272, 2013.

14. White ES, Thannickal VJ, Carskadon SL, Dickie EG, Livant DL, Markwart S, Toews GB and Arenberg DA: Integrin alpha4beta1 regulates migration across basement membranes by lung fibroblasts: A role for phosphatase and tensin homologue deleted on chromosome 10. Am J Respir Crit Care Med 168: 436-442, 2003.

15. White ES, Atrasz RG, Hu B, Phan SH, Stambolic V, Mak TW, Hogaboam CM, Flaherty KR, Martinez FJ, Kontos CD and Toews GB: Negative regulation of myofibroblast differentiation by PTEN (phosphatase and tensin homolog deleted on chromosome 10). Am J Respir Crit Care Med 173: 112-121, 2006.

16. Miyoshi K, Yanagi S, Kawahara K, Nishio M, Tsubouchi H, Imazu Y, Koshida R, Matsumoto N, Taguchi A, Yamashita S, et al: Epithelial Pten controls acute lung injury and fibrosis by regulating alveolar epithelial cell integrity. Am J Respir Crit Care Med 187: 262-275, 2013.

17. Xia H, Khalil W, Kahm J, Jessurun J, Kleidon J and Henke CA: Pathologic caveolin-1 regulation of PTEN in idiopathic pulmonary fibrosis. Am J Pathol 176: 2626-2637, 2010.

18. Xia H, Diebold D, Nho R, Perlman D, Kleidon J, Kahm J, Avdulov S, Peterson M, Nerva J, Bitterman P and Henke C: Pathological integrin signaling enhances proliferation of primary lung fibroblasts from patients with idiopathic pulmonary fibrosis. J Exp Med 205: $1659-1672,2008$

19. Fagone E, Conte E, Gili E, Fruciano M, Pistorio MP, Lo Furno D, Giuffrida R, Crimi N and Vancheri C: Resveratrol inhibits transforming growth factor- $\beta$-induced proliferation and differentiation of ex vivo human lung fibroblasts into myofibroblasts through ERK/Akt inhibition and PTEN restoration. Exp Lung Res 37: 162-174, 2011.

20. Desmoulière A, Geinoz A, Gabbiani Fand Gabbiani G: Transforming growth factor-beta 1 induces alpha-smooth muscle actin expression in granulation tissue myofibroblasts and in quiescent and growing cultured fibroblasts. J Cell Biol 122: 103-111, 1993.

21. Sime PJ and O'Reilly KM: Fibrosis of the lung and other tissues: New concepts in pathogenesis and treatment. Clin Immunol 99: 308-319, 2001

22. Leask A and Abraham DJ: TGF-beta signaling and the fibrotic response. FASEB J 18: 816-827, 2004

23. Kulkarni AA, Thatcher TH, Olsen KC, Maggirwar SB, Phipps RP and Sime PJ: PPAR- $\gamma$ ligands repress TGF $\beta$-induced myofibroblast differentiation by targeting the PI3K/Akt pathway: Implications for therapy of fibrosis. PLoS One 6: e15909, 2011.

24. Caraci F, Gili E, Calafiore M, Failla M, La Rosa C, Crimi N, Sortino MA, Nicoletti F, Copani A and Vancheri C: TGF-beta1 targets the GSK-3beta/beta-catenin pathway via ERK activation in the transition of human lung fibroblasts into myofibroblasts. Pharmacol Res 57: 274-282, 2008.

25. Gauldie J, Bonniaud P, Sime P, Ask K and Kolb M: TGF-beta, Smad 3 and the process of progressive fibrosis. Biochem Soc Trans 35: 661-664, 2007. 
26. Li DM and Sun H: TEP1, encoded by a candidate tumor suppressor locus, is a novel protein tyrosine phosphatase regulated by transforming growth factor beta. Cancer Res 57 2124-2129, 1997.

27. Raghu G, Collard HR, Egan JJ, Martinez FJ, Behr J, Brown KK, Colby TV, Cordier JF, Flaherty KR, Lasky JA, et al; ATS/ERS/JRS/ALAT Committee on Idiopathic Pulmonary Fibrosis: An official ATS/ERS/JRS/ALAT statement: Idiopathic pulmonary fibrosis: Evidence-based guidelines for diagnosis and management. Am J Respir Crit Care Med 183: 788-824, 2011.

28. Livak KJ and Schmittgen TD: Analysis of relative gene expression data using real-time quantitative PCR and the 2(-Delta Delta C(T)) Method. Methods 25: 402-408, 2001.

29. Nathan SD, Basavaraj A, Reichner C, Shlobin OA, Ahmad S, Kiernan J, Burton N and Barnett SD: Prevalence and impact of coronary artery disease in idiopathic pulmonary fibrosis. Respir Med 104: 1035-1041, 2010.

30. Nho RS: Current concept for the pathogenesis of idiopathic pulmonary fibrosis (IPF). Clin Res Pulmono 1: 1006-1008, 2013.

31. Nho RS, Hergert P, Kahm J, Jessurun J and Henke C: Pathological alteration of FoxO3a activity promotes idiopathic pulmonary fibrosis fibroblast proliferation on type I collagen matrix. Am J Pathol 179: 2420-30, 2011.

32. Ihn H: Pathogenesis of fibrosis: Role of TGF-beta and CTGF. Curr Opin Rheumatol 14: 681-685, 2002

33. Conte E, Fruciano M, Fagone E, Gili E, Caraci F, Iemmolo M, Crimi $\mathrm{N}$ and Vancheri $\mathrm{C}$ : Inhibition of PI3K prevents the proliferation and differentiation of human lung fibroblasts into myofibroblasts: The role of class I P110 isoforms. PLoS One 6: e24663, 2011.
34. Wilkes MC, Mitchell H, Penheiter SG, Doré JJ, Suzuki K, Edens M, Sharma DK, Pagano RE and Leof EB: Transforming growth factor-beta activation of phosphatidylinositol 3-kinase is independent of Smad2 and Smad3 and regulates fibroblast responses via p21-activated kinase-2. Cancer Res 65: 10431-10440, 2005.

35. Gu L, Zhu YJ, Yang X, Guo ZJ, Xu WB and Tian XL: Effect of TGF-beta/Smad signaling pathway on lung myofibroblast differentiation. Acta Pharmacol Sin 28: 382-391, 2007.

36. Chilosi M, Poletti V, Zamò A, Lestani M, Montagna L, Piccoli P, Pedron S, Bertaso M, Scarpa A, Murer B, et al: Aberrant Wnt/beta-catenin pathway activation in idiopathic pulmonary fibrosis. Am J Pathol 162: 1495-1502, 2003.

37. Amini Nik S, Ebrahim RP, Van Dam K, Cassiman JJ and Tejpar S: TGF-beta modulates beta-Catenin stability and signaling in mesenchymal proliferations. Exp Cell Res 313: 2887-2895, 2007.

38. Baarsma HA, Spanjer AI, Haitsma G, Engelbertink LH, Meurs H, Jonker MR, Timens W, Postma DS, Kerstjens HA and Gosens R: Activation of WNT/ $\beta$-catenin signaling in pulmonary fibroblasts by TGF- $\beta_{1}$ is increased in chronic obstructive pulmonary disease. PLoS One 6: e25450, 2011.

39. Pardo A and Selman M: Matrix metalloproteases in aberrant fibrotic tissue remodeling. Proc Am Thorac Soc 3: 383-388, 2006.

40. Jarman ER, Khambata VS, Yun Ye L, Cheung K, Thomas M, Duggan N and Jarai G: A translational preclinical model of interstitial pulmonary fibrosis and pulmonary hypertension: mechanistic pathways driving disease pathophysiology. Physiol Rep 2: e12133, 2014. 